\title{
IDIOPATHIC THROMBOCYTOPENIC PURPURA (ITP);
}

\author{
Frequency of clinical features in children
}

Dr. Itaat ullah Khan Afridi, Dr. Munazza Saqib

ABSTRACT.....Objective: To find the frequency of common clinical features of Idiopathic Thrombocytopenic Purpura (ITP) in children and to see whether bone marrow aspiration needed in every child with typical presentation of ITP. Design: Cross-sectional study. Setting: Hematology/Oncology Department, the Children Hospital \& the Institute of Child Health Lahore Pakistan. Duration: April 2008 to March 2009 (One year). Material and Methods: A total of 30 children presenting with bleeding through any orifice with diagnostic evidence of ITP were evaluated by a cross sectional study. Common clinical features were recorded along with the related hematological parameters. After taking detailed history and thorough examination, relevant investigations like peripheral smear, bleeding time and coagulation screen were carried out in all cases. Bone marrow examination was done only in selected cases. The cases were then managed according to standardized management criteria. Results: Male: Female ratio was $3: 2$, age ranging from 18 months to 14 years (mean \pm SD of $5.2 \pm$ years) with median age of 5.2 years. $26.6 \%(n=08)$ patients were having preceded history of upper respiratory tract infection. The positive clinical findings were bruises in $30 \%(n=09)$ cases; petechiae in $23.3 \%(n=07)$ cases; epistaxis in $23.3 \%(n=07)$ cases; gum bleeding in $13.3 \%(n=04)$ cases and hematuria only in $10 \%(n=03)$ cases. Anemia $(<9 \mathrm{gm} \%)$ was noted in $40 \%(n=12)$ patients. On peripheral smear examination this was microctic hypochromic in nature. Bleeding time was prolonged in all patients in line with documented thrombocytopenia i.e platelet count $<150,000$. PT/APTT was normal in all 30 patients. Conclusions: Bruises, Petechiae and epistaxis are the commonest clinical findings of ITP. Bone marrow aspiration revealed inconclusive results in such cases.

Key words: ITP, Bruises, Petechiae and epistaxis

Article Citation

Afridi IUK, Saqib M. Idiopathic Thrombocytopenic Purpura (ITP); Frequency of clinical features of in children. Professional Med J 2013;20(2): 188-192.

\section{INTRODUCTION}

The onset of thrombocytopenia in an otherwise well child, in the absence of any underlying cause or apparent associated condition is Idiopathic thrombocytopenic purpura (ITP) also known as immune thrombocytopenic purpura and is the commonest cause of thrombocytopenia in childhood ${ }^{1}$, ${ }^{2}$ with reported Incidence of 4-6 per 100,000 children peryear, ${ }^{3,8}$.

ITP can be classified into two major forms i.e. acute and chronic ITP. Incidence of ITP is 4-6 per 100000 children per year ${ }^{3}$.In Pakistan, the diagnosis of ITP may constitute up to $32 \%$ of admitted cases of childhood thrombocytopenia. ${ }^{4}$ It results from an immune mediated destruction of circulating platelets within the reticuloendothelial system, mainly in the spleen. The exact antigenic target for such antibodies remains undetermined ${ }^{1}$.The reduced platelet count is accompanied by a compensatory increase in megakaryocytes within the bone marrow. ITP is a cause of concern to parents because all of a sudden a child develops bruises / epistaxis and other mucosal bleeding without any warning, mainly affects children between 2 and 10 years of age ${ }^{5,6,7}$.

By definition acute ITP is characterized by :

1) Thrombocytopenia ; peripheral platelet count $<150,000 \times 10^{9} / \mathrm{L}$

2) Purpuric rash

3) Normal bone marrow

4) Absence of signs of other identifiable causes of thrombocytopenia ${ }^{8}$.

ITP is usually acute and self-limiting disease in $90 \%$ of the children ${ }^{1,9}$. Most will require only a brief stay in hospital to confirm the diagnosis and assess its severity. There has been much debate about the need to perform a bone marrow aspiration to exclude malignant infiltration or aplasia. If the clinical features 
are characteristic, with no abnormality in the blood other than a low platelet count and there is no intention to treat, there is no need to examine the bone marrow ${ }^{1}$. It is acknowledged that acute childhood ITP resolves spontaneously within 6 months, irrespective of drug therapy. Although life threatening risk of intracranial hemorrhage is quite rare $^{10}$ but the commonly encountered severe thrombocytopenia and the risk of serious bleeding complications such as gastrointestinal or intracranial hemorrhage ${ }^{11}$ compel the physicians to prescribe drug treatment ${ }^{1}$.

Choice of therapy depends upon the clinical situation, number of platelets and sometimes on availability of drugs, If the child has minor purpura and platelet counts are greater than $30,000 / \mathrm{mm} 3$ the child should be treated conservatively ${ }^{12}$. Children with platelet counts $<20,000 / \mathrm{mm}^{3}$ and significant mucous membrane bleeding have to be treated with specific regimens of glucocorticoids or intravenous immunoglobulins $(\mathrm{IVIg})^{13}$. Children who have lifethreatening bleeding should be hospitalized. They should receive conventional critical care measures along with treatment of ITP. Appropriate regimens include high dose parenteral glucocorticoid therapy, platelet transfusions and $\mathrm{IVIg}^{14}$. The objective of this study was to find out the frequency of various clinical findings in children with ITP and identify the benefits of doing bone marrow in subset of such cases.

\section{MATERIAL \& METHODS}

This study was conducted at Hematology/Oncology Department, The Children Hospital \& the Institute of Child Health Lahore Pakistan, over a period of one year from April 2008 to March 2009.

A total of 30 patients were included in this study. Any child aged less than 15 years with isolated thrombocytopenia with bleeding from any site was included, patients with aplastic anemia, patients with other causes of thrombocytopenia such as SLE etc and neonatal thrombocytopenia were excluded. All relevant information including detailed history of presentation, history of recent viral infection, family history of bleeding disorder, history of drug intake and positive findings on physical examination and investigations was recorded on pre-designed proforma.

Detailed physical examination was done to look for evidence of bleeding in the skin and mucous membranes. During clinical examination we specifically looked for lymph nodes enlargement, hepato-splenomegaly, weight loss and bony tenderness \& bone pains.

Investigations included complete blood count including Hemoglobin, TLC, DLC, ESR, peripheral smear, bleeding time and coagulation profile.

Bone marrow examination was also done in selected cases only.

Patients who were having significant bleeding from the mucous membranes or platelet count less than $20,000 / \mathrm{mm}^{3}$ were managed with pharmacological treatment (oral steroids for 2 weeks, 2 - $4 \mathrm{mg} / \mathrm{kg}$ followed by tapering over next week).

\section{RESULTS}

Male: Female ratio was3:2, age ranging from 18 months to 14 years (mean $\pm S D$ of $5.2 \pm$ years). There were more cases of age less than 5 years with median age of 5.2 years.

26.6\% $(n=08)$ patients were having preceded history of upper respiratory tract infection.

The positive clinical findings were bruises in $30 \%$ $(n=09)$ cases; petechiae in $23.3 \%(n=07)$ cases; epistaxis in $23.3 \%(n=07)$ cases; gum bleeding in $13.3 \%(n=04)$ cases and hematuria only in $10 \%$ $(n=03)$ cases. 
There was no case having organomegaly or lymphadenopathy.

Regarding laboratory findings anemiae $(<9 \mathrm{gm} \%)$ was noted in $40 \%(n=12)$ patients. On peripheral smear examination this was microctic hypochromic in nature.

Bleeding time was prolonged in all patients in line with documented thrombocytopenia i.e platelet count $<$ 150,000.PT/APTT was normal in all 30 patients.

Bone marrow was performed in 03 cases and biopsy findings of all three were consistent with diagnosis of

\begin{tabular}{|c|c|c|c|}
\hline Age & N & Male & Female \\
\hline 18 months to 5 years & 15 & 8 & 7 \\
\hline$>$ 5 years to 10 years & 6 & 4 & 2 \\
\hline$>10$ years to 14 years & 09 & 6 & 3 \\
\hline Total & 30 & 18 & 12 \\
\hline
\end{tabular}

Table-I. Age and sex distribution

\begin{tabular}{|l|c|c|}
\hline Positive Clinical Findings & N & \% age \\
\hline Bruising tendency & 09 & $30 \%$ \\
\hline Petechiae & 07 & $23.3 \%$ \\
\hline Epistaxis & 07 & $23.3 \%$ \\
\hline Gum bleeding & 04 & $13.3 \%$ \\
\hline Hematuria & 03 & $10 \%$ \\
\hline
\end{tabular}

Table-II. Positive Clinical Findings among ITP cases

\begin{tabular}{|l|c|c|c|}
\hline Lab Findings & Cutt-off / value & N & $\%$ age \\
\hline Platelet count & $\begin{array}{c}<150,000 \\
<20,000\end{array}$ & 30 & $100 \%$ \\
& 03 & $10 \%$ \\
\hline Bleeding time & PROLONGED & 30 & $100 \%$ \\
\hline Hemoglobin & $<9 g m / d l$ & 12 & $40 \%$ \\
\hline Bone marrow biopsy & Megakariocytosis & 03 & $10 \%$ \\
\hline
\end{tabular}

Table-III. Positive Laboratory Findings among ITP cases
ITP.

\section{DISCUSSION}

Idiopathic thrombocytopenic purpura (ITP) affects children comparatively more in younger age groups ${ }^{6}$. In our study children less than 5 years constitute $50 \%$ out of children of the age ranging from 18 months to 16 years and hence this findings persisted in our study as well. Similar results were reported by Ahn \& Horstman, who observed a higher incidence of the disease in children aged 2 to 4 years among the children diagnosed with acute ITP ${ }^{15}$.

Male children are affected more as compared to female children ${ }^{16}$. This finding is equally present in our study and similar results were observed in a study byNaima Al-Mulla et al' ${ }^{17}$.

The most common clinical presentation in our study was bruises followed by petechiae and epistaxis, similar results were observed in a study conducted at Peshawar in 2004,reported bruises in $40 \%$ and epistaxis in $20 \%$ of patients as initial presentation of ITP. John D Grainger, et al also observed the similar results in their study?

Findings on peripheral smear examination (microcytic \& hypochromic) of the patients having hemoglobin of less than $9 \mathrm{gm} \%$ was also reported by Musa Kalim et $a l^{5}$.

Bleeding time was prolonged in all patients because there was documented thrombocytopenia i.e platelet count $<150,000$ in $100 \%$ of patients.PT/APTT was normal as expected in all patients, all these findings were also present in a study done by Jan Mohammad et al in $2010^{4}$. Bone marrow was done in 03 patients and the results were consistent with diagnosis of ITP.

In 03 patients having platelet count of $<20,000$ and treated with oral steroids for 2 weeks with a dose of 2 $4 \mathrm{mg} / \mathrm{kg}$ followed by tapering over next week showed good response and their platelet count returned to 
normal. Similar results were found in the studies done by Aumann $\mathrm{V}$ et al ${ }^{14}$ and Jan Mohammad et al ${ }^{4}$.

\section{CONCLUSIONS}

Bruises, Petechiae and epistaxis are the commonest clinical findings of ITP. Platelet counts above 20,000/ $\mathrm{mm}^{3}$ usually do not require any special treatment if asymptomatic. If the clinical features are characteristic, with no abnormality in the blood other than a low platelet count and there is no intention to treat, there is no need to examine the bone marrow.

\section{Copyright(c) 10 Jan, 2013.}

\section{REFERENCES}

1. V. Gupta, V. Tilak, B.D. Bhatia. Immune thrombocytopenic Purpura. Indian J Pediatr2008; 75 (7) : 723-728.

2. Rodeghiero F, Stasi R, Gernsheimer T, et al. Standarization of terminology, definations and outcome criteria in immune thrombocytopenic purpura of adults and children: report from an international working group. Blood. 2009; 113 : 238693.

3. Chu Yu - Waye, Korb J, Sackamoto KM. Idiopathic thrombocytopenic purpura. Pediatrics in review 2000; 21:91-104.

4. Jan MA. Thrombocytopenia in children. J Postgrad Med Inst Sep 2004; 18(3) : 353-58.

5. Kalim M, Ali L, KhattakAA . Childhood Idiopathic Thrombocytopenia.: Clinical Profile and management. JPMI 2005 Vol 19 No. 1: 101-105.

6. Wilson DB. Acquired platelet defects. In Nathan DG, OrkinSH,eds. Nathan \& Oski's Hematology of infancy and childhood.6 $6^{\text {th }}$ edn. Philadelphia, WB Saunders Company , 2002;1: 1597-1630.
7. Grainger JD, Rees JL, Reeves M, Bolton - Maggs PHB. Changing trends in the UK Management of childhood ITP. Arc Dis Child.2012; 97: 8-11.

8. Ali AS, et all. Idiopathic thrombocytopenic purpura initial illness and subsequent behavior. Pak Pediat $J$ 2005; 29(2) : 93-99.

9. Claden LT. Illustrated Textbook of paediatrics. $2^{\text {md }}$ edn, St Mary's hospital , London ,2001;311-12.

10. AbshireT, Chijdhood ITP: Can we venture below 20000. Blood. 2008; vol.112No.10:3918-3919.

11. Psaila B, Petrovic A, Page LK, et al. Intracranial hemorrhage (ICH) in children with immune thrombocytopenia (ITP) : study of $\mathbf{4 0}$ cases. Blood $2009 ; 114: 4777-83$.

12. Field MJ, Lohr KN. Guidelines of clinical practice: From development to use. Institute of medicine committee on clinical practice guidelines. Washington DC: National Academy Press, 1992.

13. Woolf SH Practice guidelines: A new reality in medicine, III. Impact on patient care. Arch Intern Med 1993; 153: 2646-48.

14. Aumann V, Miltter U Kluba U. Therapy of idiopathic thrombocytopenic purpura. Arch Dis Child 1994;71: 251-53.

15. Ahn YS, Horstman LL. Idiopathic thrombocytopenic purpura : pathophysiology and management. Int J Hematol . 2002; 76 Suppl 2: 123-31.

16. Liley JS, Hann IM, Blanchette VS (eds) paediatric hematology, $2^{\text {nd }}$ ed. Churcil Livingstone. Edinburgh. 1999. 27-35.

17. Al-m ulla N, Bener A, Amer A, Abu Laban M. Idiopathic thrombocytopenic purpura. J Pediatr (Rio J).2009;85(3):269-272. 


\section{AUTHOR(S):}

1. DR. ITAAT ULLAH KHAN AFRIDI

FCPS (Peads)

Assistant Professor Pediatrics,

Akhtar Saeed Medical \& Dental College,

Tulip Block Sector C Bahria Town, Lahore, Pakistan

2. DR. MUNAZZA SAQIB

MCPS, FCPS

Assistant Professor Dermatology,

Akhtar Saeed Medical \& Dental College,

Tulip Block Sector C Bahria Town, Lahore, Pakistan
Correspondence Address:

Dr. Itaat Ullah Khan Afridi

FCPS (Peads)

Assistant Professor Pediatrics,

Akhtar Saeed Medical \& Dental College,

Tulip Block Sector C Bahria Town, Lahore, Pakistan

itaatafridi@yahoo.com

\section{PREVIOUS RELATED STUDIES}

Ahmed Khan Chaudhry, Mihammad Azam. SPLENECTOMY IN IDIOPATHIC THROMBOCYTOPENIA (A RETROSPECTIVE REVIEW) (Original) Prof Med Jour 11(2) 190-196 Apr, May, Jun, 2004.

Electronic submission saves time, postage costs and allows the manuscript
to be handled in electronic form throughout the publication process.
Accepts electronic submission of articles via e-mail, attachment in
MS Word format at following address:
info@theprofesional.com
editor@theprofesional.com
publication@theprofesional.com
for more details, visit us ;
www.theprofesional.com

